\title{
Precipitating electrons: Evidence for effects on mesospheric odd nitrogen
}

\author{
Linwood B. Callis ${ }^{1}$, Robert E. Boughner ${ }^{1}$, Daniel N. Baker ${ }^{2}$, \\ Richard A. Mewaldt ${ }^{3}$, J. Bernard Blake ${ }^{4}$, Richard S. Selesnick ${ }^{3}$, \\ Jay R. Cummings ${ }^{3}$, Murali Natarajan ${ }^{5}$ \\ Glenn M. Mason ${ }^{6}$, and Joseph E. Mazur ${ }^{6}$
}

\begin{abstract}
Observations of electron fluxes made by the PET and LICA instruments aboard SAMPEX have been used with NO measurements made by HALOE aboard UARS to provide evidence of mesospheric and lower thermospheric NO formation due to precipitating electrons. Results indicate significant NO increases from 70 to $120 \mathrm{~km}$ which are associated with the occurrence of enhanced electron populations in the outer trapping regions of the magnetosphere, $2.5 \leq L \leq 7$, which precipitate into the atmosphere.
\end{abstract}

\section{Introduction}

Interannual variations in the hemispheric column $\mathrm{NO}_{2}$ of up to $35 \%$, as measured above $25 \mathrm{~km}$ at sunset by SAGE II, have been reported by Callis et al. [1991a] and Callis [1994]. These authors have suggested that these changes are, in part, due to a time varying source of odd nitrogen $\left(\mathrm{NO}_{\mathrm{y}}\right)$ in the mesosphere and at mid to high latitudes driven by fluctuations in relativistic electron precipitation from the outer trapping region of the magnetosphere.

With the availability of electron data from the Proton Electron Telescope (PET) and the Low Energy Ion Composition Analyzer (LICA) instruments aboard the Solar Anomalous and Magnetospheric Particle Explorer (SAMPEX) and NO data from the Halogen Occultation Experiment (HALOE) aboard the Upper Atmospheric Research Satellite (UARS) studies can now be conducted to examine a possible link between electron precipitation and NO formation.

The task of finding NO increases that may be due to electron events and then determining whether or not the observed NO increases are consistent with the en-

\footnotetext{
${ }^{1}$ ASD, NASA-Langley Research Center, Hampton, VA 23681

${ }^{2}$ LASP, University of Colorado, Boulder, CO 80303

${ }^{3}$ SRL, California Institute of Technology, Pasadena, CA 91125

'Aerospace Corp., Los Angeles, CA 90009

'SAIC, Hampton, VA 23666

${ }^{6}$ University of Maryland, College Park, MD 20742
}

Copyright 1996 by the American Geophysical Union.

Paper number 96GL01787

0094-8534/96/96GL-01787\$05.00 hanced fluxes is considerably more difficult than is the case for assessing the $\mathrm{NO}_{\mathrm{y}}$ response to solar proton flux enhancements during intense solar flares events which occur infrequently and last 1-3 days. The enhanced proton fluxes generally lead to $\mathrm{NO}_{\mathrm{y}}$ increases throughout both polar caps. By contrast, electron precipitation occurs all the time with significant variability and recurrent flux enhancements which can last from days to $\approx 3$ weeks. They affect the atmosphere in relatively narrow latitudinal bands $\left(5^{\circ}\right.$ to $\left.15^{\circ}\right)$ which circle the magnetic poles. Rapid horizontal transport within the mesosphere can be a complicating factor. The analysis is further complicated by the nature of the HALOE latitude-time coverage since there are only infrequent periods when a restricted latitude range can be continuously viewed for several days.

\section{Data}

SAMPEX was launched into an $82^{\circ}$ orbit with an altitude of $\approx 600 \mathrm{~km}$ on July 3,1992. An overview of the SAMPEX mission is given by Baker et al. [1993] and descriptions of the PET and LICA instruments are provided by Cook et al. [1993] and Mason et al. [1993]. These instruments provide electron measurements with up to $0.1 \mathrm{sec}$ time resolution and coverage between $\pm 82^{\circ}$ and at all longitudes, and for $\mathrm{E} \geq 0.035$ $\mathrm{MeV}$ (LICA) and E $\geq 0.40 \mathrm{MeV}$ (PET).

Events of interest are identified by looking for enhancements in the electron fluxes observed by PET which occur when HALOE provides several days of continuous observations within a confined latitude range. The $\pm 82^{\circ}$ latitudinal coverage of SAMPEX permits full advantage to be taken of the HALOE NO coverage.

The HALOE is described by Russell et al. [1993]. Measurements of NO are made at sunrise and sunset with a vertical field of view of $1.6 \mathrm{~km}$ at the Earth's limb. Normally, 15 profiles of each type are retrieved each day separated by $\approx \mathbf{2 4 ^ { \circ }}$ in longitude. Vertical coverage extends from 15 to $130 \mathrm{~km}$ for NO. Validation of the NO data is reported by Gordley et al. [1995].

\section{Data Analysis}

In the present study, we focus on NO between $\mathbf{5 0}$ and $120 \mathrm{~km}$. We examine changes in NO which occur during those periods when HALOE makes several days 

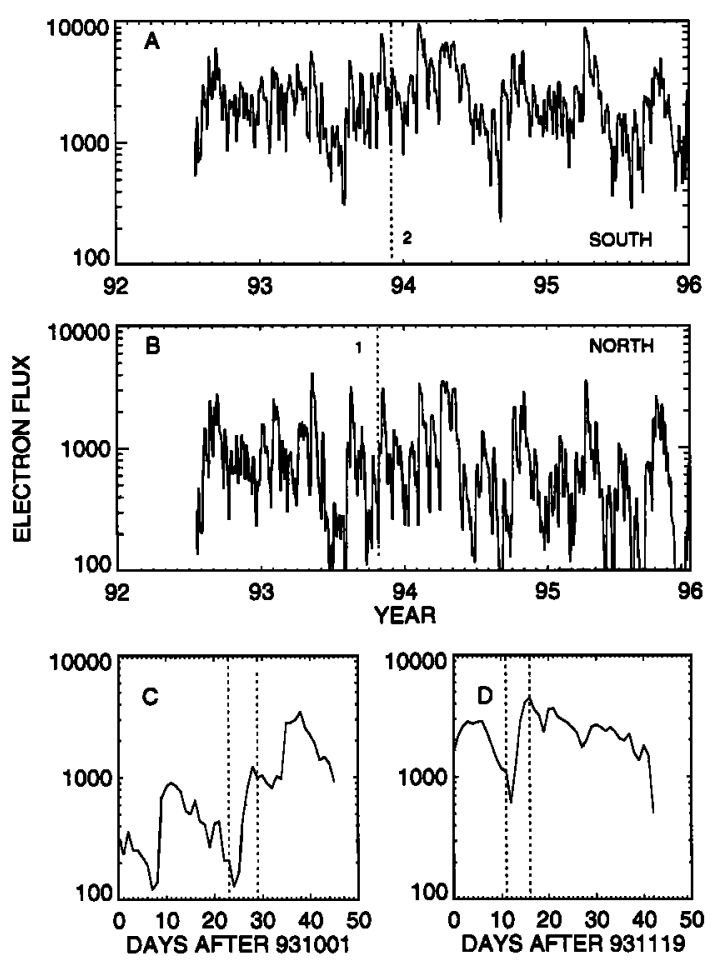

Figure 1. (a) A 3-day running average of integral electron fluxes as measured by the PET for $\mathrm{E} \geq 0.40 \mathrm{MeV}$ and between $45^{\circ}$ and $65^{\circ}$ magnetic latitude in the southern hemisphere. (b) Same as (a) except for northern hemisphere. Panels $(c)$ and $(d)$ show expanded views of the events. Units of electron fluxes are electrons $/\left(\mathrm{cm}^{2}-\right.$ sec-sr). Events 1 and 2 are shown by dotted lines.

of continuous observations within a relatively confined latitudinal range, and when an enhancement of trapped and precipitating electron fluxes occurs. Such HALOE coverage will occur when the latitudinal orbital track reverses direction. During such periods, the observations which are used are either all sunrise or all sunset.

Figure 1 illustrates the history of electron fluxes for for magnetic latitudes $45^{\circ}-65^{\circ}$ for both hemispheres as measured by PET. This figure illustrates the hemispheric differences and the rapid and large variations in the flux. Events may last from days to weeks. The dotted lines on Figures $1 a, b$ indicate the start of the two events observed by SAMPEX which we will examine in this paper. Figures $1 c, d$ illustrate the extent of the events examined. The electron events selected are not the strongest, the weakest, or the ones with the longest duration.

Figure $2 a$ illustrates the history of the normalized integral electron flux observed by PET and LICA and two NO column abundances (51-120 km and 51-81 km) for event 1 . As indicated on Figure $2 a$, in a 5-day interval, the PET and LICA electron fluxes increase by factors of $\approx 8$ and $\approx 18$, respectively, and the sunrise NO columns by factors of $\approx 2.3-2.4$. During this 5-day period, HALOE sunrise observations were confined to latitudes between $54.8^{\circ}$ and $54.1^{\circ}$.
Figure $2 b$ presents the daily average of the HALOE sunrise NO profiles, for 931024 (93297) and 931029 (93302). These profiles indicate increases of NO during this period at altitudes above $60 \mathrm{~km}$ with significant increases found at all altitudes between 70 and $\approx 120 \mathrm{~km}$. The vertical integral $(51-120 \mathrm{~km})$ of NO increased from $2.43\left(10^{14}\right)$ to $5.79\left(10^{14}\right)$ molecules $/ \mathrm{cm}^{2}$, an increase of $138 \%$. For the column from $51-81 \mathrm{~km}$, the fractional increase is similar but the absolute increase was an order of magnitude smaller. Quality numbers provided with the HALOE data are the random errors in NO. The error bars shown have been derived accordingly. For signal-to-noise ratios $(\mathrm{S} / \mathrm{N}) \leq 0.5$, the NO measured is taken to represent an upper limit of the measurement [J. M. Russell, III, Private Communication, 1996].

Figures $3 a, b$ present similar results for event 2. Figure $3 a$ shows an increase in the PET and LICA electron fluxes by a factors of $\approx 6$ and 7 , respectively, over 3-5 days with an increase in the 51-120 km sunrise column NO by $196 \%$ and in the $51-81 \mathrm{~km}$ column by $30 \%$. Figure $3 b$ illustrates the daily averaged sunrise NO profiles as observed from HALOE for $\mathbf{9 3 1 1 3 0}$ (93334) and 931203 (93337). The latitude range ob-
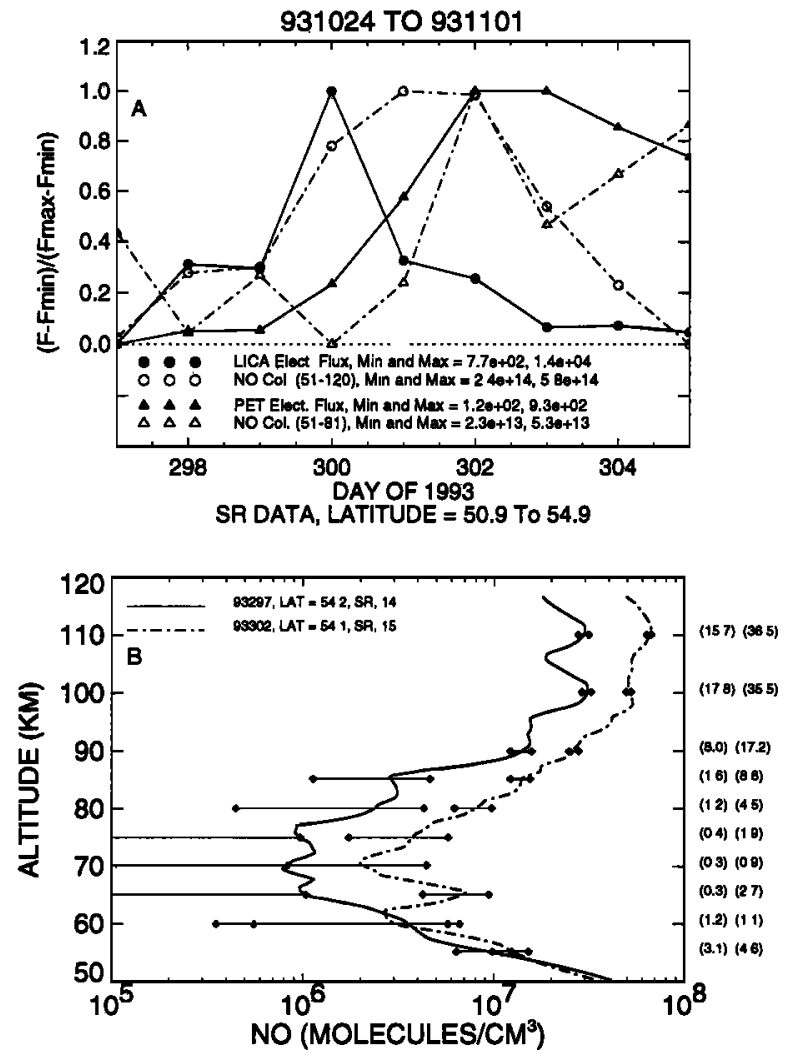

Figure 2. (a) Normalized history of electron flux for $\mathrm{E} \geq 0.40 \mathrm{MeV}$ (PET), for $\mathrm{E} \geq \mathbf{0 . 0 3 5} \mathrm{MeV}$ (LICA), and column NO between 51 and $120 \mathrm{~km}$ and between 51 and $81 \mathrm{~km}$ for the periods indicated. Electron fluxes and column NO units are electrons $/\left(\mathrm{cm}^{2}\right.$-sec-sr $)$ and molecules $/ \mathrm{cm}^{2}$. (b) Day-average profiles of NO concentrations for the dates and latitudes shown. SR refers to sunrise scans. The number of scans included in the average are shown on the legend. S/N ratios for both profiles are shown to the side of the figure. 

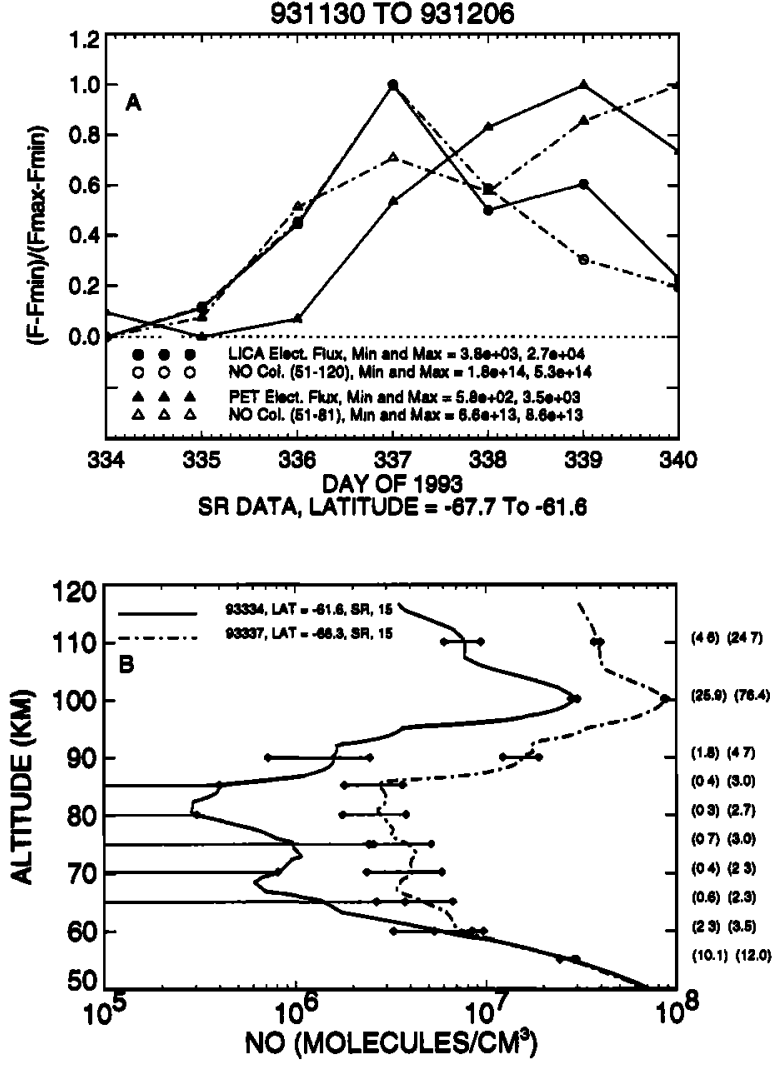

Figure 3. (a) Same as for $2 a$ except for the dates and latitudes indicated. (b) Same as for 2(b) except for the dates and latitudes indicated.

served by HALOE for this period was $-60.7^{\circ}$ to $-66.8^{\circ}$. This event is of particular interest since the meridional advective transport fields indicate upward motion at altitudes above $\approx 40 \mathrm{~km}$, and the time of year is such that there is no polar night in this hemisphere (see discussion below). The increase in the LICA flux at day 339 with no corresponding increase in $51-120 \mathrm{~km}$ NO column is of interest. Examination of the LICA data indicate that these flux increases occurred in a confined range of longitudes $\left(20^{\circ}-70^{\circ} \mathrm{E}\right)$ and the $\mathrm{NO}$ at the peak of these increases $\left(50^{\circ} \mathrm{E}\right)$ is not observed by HALOE on that day.

\section{Electron spectra for events}

In the present work we present two precipitating electron spectra in the appropriate time periods and latitude ranges for the two events discussed here. These spectra have been used in a deposition code [Walt et al., 1968] which is then used to calculate the $\mathrm{NO}_{\text {, for- }}$ mation rates to see if they are nominally consistent with the observed increases in NO observed by HALOE. We assume $1.2 \mathrm{NO}_{\mathrm{y}}$ produced per ion pair formed.

The electron spectra in Figure 4 are derived from PET assuming an isotropic pitch angle distribution and a two-part exponential variation with a break at $1 \mathrm{MeV}$. The simulated and observed counting rates for $E \geq 0.4$ $\mathrm{MeV}$ are matched, and the counting rates for $1.5 \leq \overline{\mathrm{E}} \leq 6$
$\mathrm{MeV}$ (ELO, nominal), and $2.6 \leq \mathrm{E} \leq 10 \mathrm{MeV}$ (EHI, nominal) are closely approximated. Corrections for live time and chance coincidences effects have been applied. Spectra were derived for every 6 seconds and averaged. We have extended the spectrum down to $0.10 \mathrm{MeV}$ using the e-folding energy derived for the $0.4 \leq \mathrm{E} \leq 1.0 \mathrm{MeV}$ interval. Based on results in [Callis et al., 1991a], this approximation, though helpful, will still result in an underestimate of the low energy electron flux.

In Figure 4 we also show the $\mathrm{NO}_{\mathrm{y}}$ formation rates assuming 1.2/(ion pair) [Callis et al., 1991 a]. At altitudes of $\approx 65 \mathrm{~km}$, formation rates are $\approx 10^{6}$ molecules $/ \mathrm{cm}^{3}$ day, reaching a maximum near $72 \mathrm{~km}$. For the same period and latitudes, we examined the archived energy deposition data derived from the PEM instrument and find deposition profiles which also indicate $\mathrm{NO}_{\mathrm{y}}$ formation rates of $\approx 10^{6}$ molecules $/ \mathrm{cm}^{3}$-day at $65 \mathrm{~km}$. Near $90 \mathrm{~km}$, however, PEM data show formation rates of $10^{7}-10^{9}$ molecules $/ \mathrm{cm}^{3}$-day. The much larger formation rates at $90 \mathrm{~km}$ derived from PEM (compared to PET) are due to the inclusion in the deposition calculations of electrons with $\mathrm{E} \geq 1 \mathrm{ev}$ [Winningham et al., 1993]. These deposition profiles indicate that substantive middle atmospheric $\mathrm{NO}_{\mathrm{y}}$ formation is occurring.

\section{Discussion and Conclusions}

Figures 2-4 provide what we believe is compelling evidence for significant production of middle atmospheric $\mathrm{NO}_{\mathrm{y}}$ due to electron precipitation from the magnetosphere. Figures $2 a$ and $3 a$ illustrate histories of electron fluxes and NO ( $\approx \mathrm{NO}_{\mathrm{y}}$ ) columns during electron events observed by SAMPEX in both hemispheres. NO columns from $51-120 \mathrm{~km}$ were observed to increase by 2.4-3.5 $\left(10^{14}\right)$ molecules $/ \mathrm{cm}^{2}$ in just 3-4 days with increases beyond the error bars extending from $\approx 70-120$ $\mathrm{km}$. Such changes represent an increase in the middle atmospheric column $\mathrm{NO}_{\mathrm{J}}(22-120 \mathrm{~km})$ by a significant 2.5-3.4\% for single events. The NO column histories and profiles (shown on Figures 2 and 3 ) show the NO

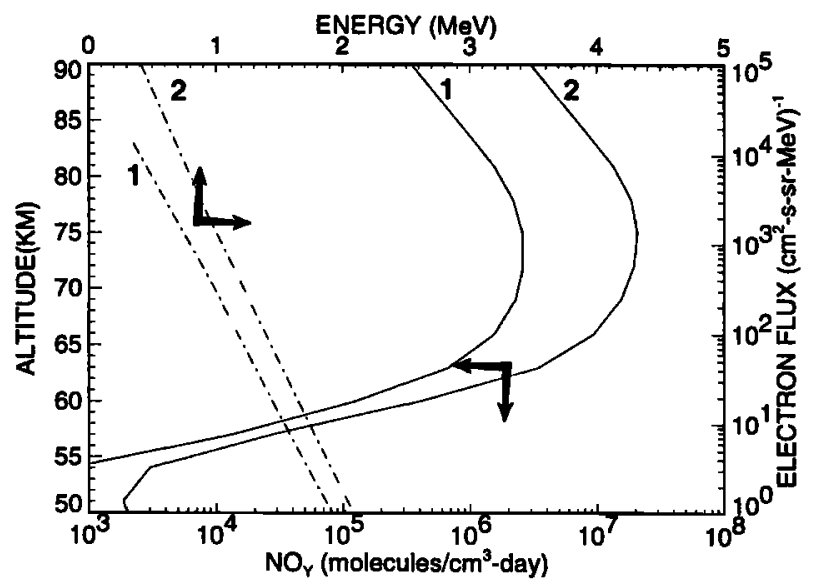

Figure 4. Electron differential flux spectra and NO formation rate profiles for events 1 and 2 . For event 1 the date and latitudes are 931028 and $53^{\circ}$ to $55^{\circ}$. For event 2 they are 931205 and $-66^{\circ}$ to $-64^{\circ}$. 
Table 1. Electron Events

\begin{tabular}{lll}
\hline Date & Latitude & NO \\
\hline $920928-921002$ & $67^{\circ}-70^{\circ} \mathrm{S}$ & $\mathrm{SR}^{1}$ \\
$921025-921030$ & $50^{\circ}-53^{\circ} \mathrm{N}$ & $\mathrm{SR}$ \\
$930602-930605$ & $61^{\circ}-66^{\circ} \mathrm{N}$ & SR \\
$930815-930817$ & $67^{\circ}-70^{\circ} \mathrm{N}$ & SR \\
$930912-930914$ & $47^{\circ}-52^{\circ} \mathrm{S}$ & SR \\
$931008-931010$ & $73^{\circ}-75^{\circ} \mathrm{S}$ & SS \\
$940205-940208$ & $51^{\circ}-52^{\circ} \mathrm{N}$ & SS \\
$940527-940530$ & $58^{\circ}-64^{\circ} \mathrm{N}$ & SR \\
$941022-941024$ & $55^{\circ}-56^{\circ} \mathrm{N}$ & SR \\
$950311-950314$ & $57^{\circ}-61^{\circ} \mathrm{N}$ & SR
\end{tabular}

${ }^{1}$ SR (SS) = sunrise (sunset) NO

changes to be dominated by increases above $80-85 \mathrm{~km}$ due to precipitating electrons with $\mathrm{E} \leq 1.0 \mathrm{MeV}$.

Figures $2 a$ and $3 a$ show that during these electron events, low energy electrons increase first followed 1-2 days later by those with higher energies. This is expected based on studies by Callis et al. [1991a]. The two NO columns shown on Figure $2 a$ reflect this with the increase in NO for the 51-81 km lagging the 51-120 increase by 1-2 days. For event number 2 shown on Figure $3 a$, the situation is slightly different. Both columns show increases beginning at essentially the same time. The $51-81 \mathrm{~km}$ column continues to increase with increases in the PET flux until day 93339 while the 51-120 $\mathrm{km}$ column, dominated by high altitude NO, begins to decline when the LICA electron flux declines. The difference in these two cases can be attributed to the differences in the spectra and deposition profiles for these two events. As shown on Figure 4, the spectrum for event 2 leads to a deposition profile with higher $\mathrm{NO}_{\mathrm{y}}$ formation rates occurring much deeper in the atmosphere. At 65 $\mathrm{km}$, the formation rate for event 2 is $\approx 6$ times higher that that for event 1 . We caution, however, that using these deposition profiles with simple linear extrapolations to derive $\mathrm{NO}_{3}$ changes will not be accurate due to the variable quadratic nature of the $\mathrm{NO}_{\mathrm{g}}$ loss and the fact that no electrons with $\mathrm{E} \leq 100 \mathrm{keV}$ are included in the deposition calculations. The upper level deposition rates shown on Figure 4 are significantly underestimated.

Other possible causes of the NO enhancements observed by HALOE must also be considered. Above 60 $\mathrm{km}$ oxidation of $\mathrm{N}_{2} \mathrm{O}$ cannot explain the rapid increases of NO. Garcia et al. [1987] have suggested that elevated levels of $\mathrm{NO}_{\mathrm{y}}$ can be relatively quickly transported by planetary waves from the descending $\mathrm{NO}_{\mathrm{g}}$ reservoir in the polar night to mid latitudes at altitudes from 70 $100 \mathrm{~km}$. This cannot be the case for event 2 since there is 24-hour sunlight at the southern pole at this time of year and since the advective transport is upward. For event 1, polar night exists only at latitudes above $77^{\circ}$ and geopotential height fields show no evidence of strong planetary wave disturbances.
We conclude that the NO increases occurring during the SAMPEX events examined are consistent with, and most likely due to, $\mathrm{NO}_{\mathrm{y}}$ formation associated with precipitating relativistic electrons, and that electron precipitation events with $\mathrm{E} \geq 35 \mathrm{keV}$, occurring in the outer trapping regions of the magnetosphere, can provide a significant source of NO for altitudes between $\approx 60$ to $120 \mathrm{~km}$. The largest absolute NO increases occur from $100-120 \mathrm{~km}$. We note that though this study only examines only two electron events observed with SAMPEX, and the associated NO increases observed by HALOE, numerous other events have been identified in the SAMPEX and HALOE data sets which show similar NO increases with some variations in magnitude. Some of these events are shown on Table 1 . In the following paper, Callis et al. [1996] assess the effects of such NO, increases on lower stratospheric $\mathrm{NO}_{5}$ and $\mathrm{O}_{3}$.

\section{References}

Baker, D. N., G. M. Mason, O. Figueroa, G. Colon, J. G. Watzin, and R. M. Aleman; An overview of the solar, anomalous, and magnetospheric particle explorer (SAMPEX) mission; IEEE Trans. on Geosci. and Remote Sensing; 31; 531; 1993.

Callis, L. B.; An examination of global variations of sunset $\mathrm{NO}_{2}$ as measured by SAGE II; Adv. Space Res.; 14; (1)219; 1994.

Callis, L. B., D. N. Baker, J. B. Blake, J. D. Lambeth, R. E. Boughner, M. Natarajan, R. W. Klebesadel, and D. J. Gorney; Precipitating relativistic electrons: Their long-term effect on stratospheric odd nitrogen levels; J. Geophys. Res.; 96; 2939; 1991 a.

Callis, L. B., R. E. Boughner, M. Natarajan, J. D. Lambeth, D. N. Baker, and J. B. Blake; Ozone depletion in the high latitude lower stratosphere: 1979-1990; J. Geophys. Res.; 96; 2921; $1991 \mathrm{~b}$.

Callis, L. B., D. N. Baker, M. Natarajan, J. B. Blake, R. A. Mewaldt, R. S. Selesnick, J. R. Cummings, A 2-D model simulation of downward transport of $\mathrm{NO}_{\mathrm{y}}$ into the stratosphere: Effects on the 1994 austral spring $\mathrm{O}_{3}$ and $\mathrm{NO}_{y}$, Geophys. Res. Lett., In Press (this issue), 1996.

Cook, W. R., et al.; PET: A proton/electron telescope for studies of magnetospheric, solar, and galactic particles; IEEE Trans. on Geosci. and Remote Sensing; 31; 565; 1993.

Gordley, L. L., et al.; Validation of nitric oxide and nitrogen dioxide measurements made by HALOE for the UARS platform, Accepted by J. Geophys. Res., May 1995.

Mason, G. M., D. C. Hamilton, P. H. Walpole, K. F. Heverman, T. L. James, M. H. Lennard, and J. E. Mazur; LEICA: A low energy ion composition analyzer for the study of solar and magnetospheric heavy ions; IEEE Trans. on Geo. Sci. and Remote Sensing; 31; 549; 1993.

Russell, J. M. III, et al.; The halogen occultation experiment; J. Geophys. Res.; 98; 10,777; 1993.

Walt, M., W. M. McDonald, and W. E. Francis, Penetration of auroral electrons into the atmosphere, in Physics of the Magnetosphere, edited by R. L. Caravillano, J. F. McClay, and H. R. Radoski, p. 534, D. Reidel, Hingham, Mass., 1968.

Winningham, J. D., et al.; The UARS particle environment monitor; J. Geophys. Res.; 98; 10,649; 1993.

(received July, 6, 1995; revised May 16, 1996; accepted May 21, 1996.) 